\title{
Telomerase activity in benign and malignant human thyroid nodules
}

\author{
Myung-Ju Ahn, ${ }^{1,4}$ Kyung Tae, ${ }^{2}$ \\ Yong-Soo Park, ${ }^{1}$ In-Soon Kim, ${ }^{1}$ \\ II-Young Choi, ${ }^{1}$ Hyung-Seok Lee, ${ }^{2}$ \\ Sun-Kon Kim ${ }^{2}$ and Yong-Sung Lee ${ }^{3}$ \\ 1 Department of Internal Medicine, College of Medicine, \\ Hanyang University; Seoul, Korea \\ 2 Department of Otolaryngology, College of Medicine, Hanyang \\ University; Seoul, Korea \\ 3 Department of Biochemistry, College of Medicine, Hanyang \\ University; Seoul, Korea \\ 4 Corresponding author: Department of Internal Medicine, \\ Hanyang University KURI Hospital, 249-1 Kyomun-dong, \\ Kyunggi-do 471-020, Korea \\ Accepted 12 July 1997
}

Abbreviations: TRAP, telomeric repeat amplification protocol; ITAS, internal telomerase amplification standard

\begin{abstract}
Telomerase is a ribonucleoprotein polymerase which contains an integral RNA and synthesizes TTAGGG nucleotide repeats at the ends of chromosomes in vertebrates. Accumulated evidence has indicated that telomerase is stringently repressed in normal human somatic tissues but reactivated in immortal and cancer cells, suggesting that activation of telo-merase may play an important role in carcinogenesis. In order to assess the role of telomerase in the development of thyroid cancer, we measured the telomerase activity in 19 frozen samples obtained from patients with benign and malignant thyroid nodules by employing a recently developed sensitive PCR-based telomerase assay (telomeric repeat ampli-fication protocol: TRAP). Telomerase activity was detected in all the thyroid cancer tissues (9 of 9 ) and 4 out of 8 benign thyroid nodules showed telomerase activity. Three of thyroid cancers with high telomerase activity had an unfavorable prognosis, whereas six cancers with low telomerase activity were associated with a favorable prognosis. Interestingly, Hashimoto's thyroiditis tissues also showed telomerase activity. These results indicate that telomerase may play a key role during thyroid carcinogenesis.
\end{abstract}

Keywords: telomerase cancer, thyroid nodules, PCR, Hashmoto's thyroiditis, carcinogenesis

\section{Introduction}

Human cancers are characterized by malignant transformation and immortalization (Shay et al., 1991). However, difficulty in establishing cell lines from cancer tissue samples has led many investigators to question whether cancer cells in vivo are immortal or not (Stamps et al., 1992). It has been shown that telomere DNA shortens at chromosome ends with both in vivo and in vitro division of human somatic cells unless the termini are extended specifically by telomerase (Harley et al., 1990; Lindsey et al., 1991; Allsopp et al., 1992).

Telomerase is a ribonucleoprotein, RNA-dependent DNA polymerase and acts as a reverse transcriptaselike enzyme which maintains telomere length by adding telomeric repeat units of TTAGGG to the telomere end (Greider et al., 1985; Yu et al., 1990). It has been suggested that deregulation of telomerase may participate in cellular immortality and oncogenesis. Cells with indefinite replicative potential such as germline cells and almost all tumor cell lines and cancer tissues express telomerase activity (Counter et al., 1994; Kim et al., 1994; Nilsson et al., 1994), while normal human somatic cells show low or undetectable telomerase activity and progressively lose their telomeric sequences both with senescence in vitro and with normal in vivo aging (Hastie et al., 1990; Vaziri et al., 1994). Therefore, telomerase activation can be directly involved in cell immortalization and telomere maintenance.

The recently developed sensitive PCR-based telomerase assay (telomeric repeat amplification protocol, TRAP) makes it possible to detect the enzyme in a variety of human tumors and tumor-derived cell lines (Kim et al., 1994). With this method, we measured telomerase activity in benign and malignant human thyroid nodules to determine whether malignant progression of thyroid cancer may correlate with expression of telomerase.

\section{Materials and Methods}

\section{Detergent extracts from tissues}

Benign and malignant thyroid nodules were obtained from each of 19 patients during surgery (Hanyang University KURI Hospital). Each tissue sample consisting of $100 \mathrm{mg}$ of frozen tissue $\left(-70^{\circ} \mathrm{C}\right)$ was washed in ice-cold wash buffer [10 mM Hepes-KOH (pH 7.5), $1.5 \mathrm{mM} \mathrm{MgCl}_{2}, 10 \mathrm{mM}$ 
$\mathrm{KCl}, 1 \mathrm{mM}$ dithiothreitol (DTT)], and then homogenized in Kontes tube with matching pestles rotated at $450 \mathrm{rpm}$ with $200 \mu \mathrm{l}$ of ice-cold lysis buffer [10 mM tris- $\mathrm{HCl}(\mathrm{pH} 7.5)$, $1 \mathrm{mM} \mathrm{MgCl}$, $1 \mathrm{mM}$ EGTA, $0.1 \mathrm{mM}$ phenylmethylsulfonyl fluoride, $5 \mathrm{mM} \beta$-mercaptoethanol, 0.5\% CHAPS, 10\% glycerol]. The lysate was incubated for $30 \mathrm{~min}$ on ice and then centrifuged for $30 \mathrm{~min}$ in a microcentrifuge $(16,000$ $g, 4^{\circ} \mathrm{C}$ ). Human 293 kidney cells (immortalized cell line) and NB4 cells (acute promyelocytic leukemia cell line) which would serve as a positive control were collected by scraping $100-\mathrm{mm}$ dishes, washed twice with ice-cold phosphate buffered saline (PBS), once with ice-cold wash buffer, and centrifuged at $3,000 \mathrm{~g}$ for $5 \mathrm{~min}$ at $4^{\circ} \mathrm{C}$. The pellets were resuspended in $200 \mu$ of ice-cold lysis buffer per $1 \times 106$ cells, and processed in the same way as the preparation of tissue extracts. The supernatant was obtained, quickly frozen in liquid nitrogen, and stored at $-70^{\circ} \mathrm{C}$.

\section{Amplification of telomeric repeat}

Telomerase activity was assayed by using the modified TRAP method (Kim et al., 1994). In brief, $0.1 \mu \mathrm{g}$ of lyophilizing CX primer ( $5^{\prime}-\{$ СССТTA 3 CCCTAA-3) was dropped onto the bottom of a tube and we sealed it with $100 \mu$ l of wax (Ampliwax, Perkin-Elmer Cetus Corp., Foster City, CA) to prepare the assay tubes. After the wax was allowed to solidify at room temperature, the tubes were

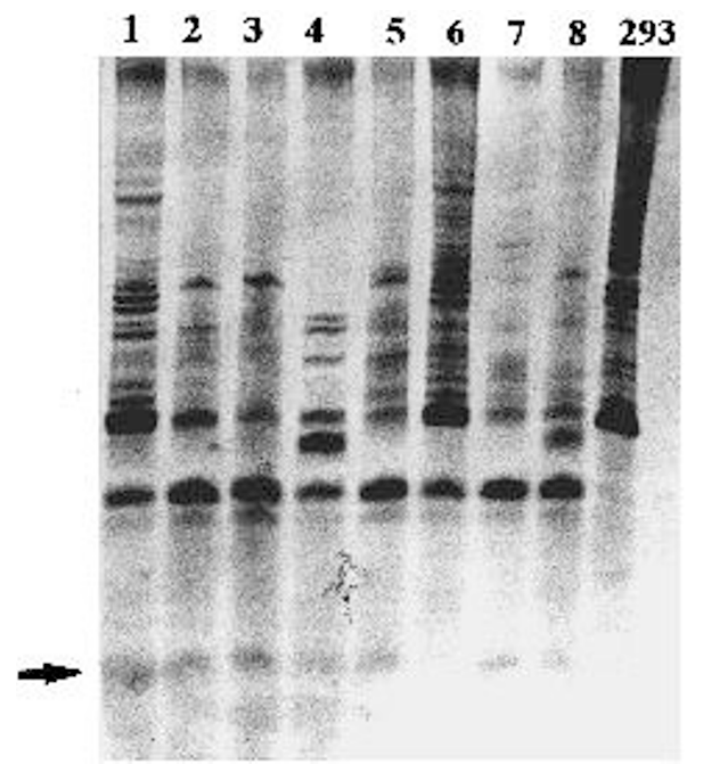

Figure 1. Telomerase activity in thyroid cancer tissues. All the thyroid cancer tissues revealed telomerase activity which appeared as characteristic 6 base pair ladder. Human 293 kidney cells served as a positive control (293). Enzyme assay was performed by using TRAP method (Kim et al., 1994). Reaction products were electrophoresed on $15 \%$ polyacrylamide nondenaturing gels and visualized with silver staining. Arrow indicates the ITAS primers to control for the presence of Taq polymerase inhibitors. stored at $4^{\circ} \mathrm{C}$. Fifty microliter of TRAP reaction mixture above the wax barrier consisted of $20 \mathrm{mM}$ tris- $\mathrm{HCl}(\mathrm{pH}$ 8.3), $1.5 \mathrm{mM} \mathrm{MgCl}$, $63 \mathrm{mM} \mathrm{KCl}, 0.005 \%$ Tween-20, $1 \mathrm{mM}$ EGTA, $50 \mu \mathrm{M}$ deoxynucleoside triphosphates, $0.1 \mu \mathrm{g}$ of TS primer (5'-AATCCGTCGAGCAGAGTT-3), 2U of Taq polymerase (Promega, Madison, $\mathrm{WI}$ ) and $6 \mu \mathrm{g}$ of protein from each CHAPS cell extract. To control for the presence of Taq polymerase inhibitors (Wright et al., 1995), the internal telomerase amplification standard (ITAS) primers were included in each analysis. Given $10 \mathrm{~min}$ at $30^{\circ} \mathrm{C}$ for telomerase to extend oligonucleotide TS, the assay tubes were transferred to the thermal cycler (Robocycler 40; Stratagene, La Jolla, CA) for 35 rounds at $94^{\circ} \mathrm{C}$ for $30 \mathrm{~s}$, $50^{\circ} \mathrm{C}$ for $30 \mathrm{~s}$, and $72^{\circ} \mathrm{C}$ for $45 \mathrm{~s}$. The resulting solution was analyzed by using electrophoresis in $1 \times$ tris-borate EDTA (TBE) buffer on $15 \%$ polyacrylamide nondenaturing gels. Silver staining method was used for visualizing the PCR products after electrophoresis. For an approximate estimation of telomerase activity, positive extracts were re-examined by serial dilution. Extracts that had been diluted both 10 times and 100 times contained $0.6 \mu \mathrm{g}$ and $0.06 \mu \mathrm{g}$ of protein, respectively (Hiyama et al., 1995).

\section{Results}

Telomerase activity was detected in all the thyroid cancer tissues (9 of 9 ) and representative results are shown in Figure 1. Irrespective of clinical characteristics, all the papillary cancer tissues showed telomerase activity and one follicular cancer and one squamous cell cancer tissue was also positive to telomerase, whereas three adjacent normal tissues did not have any telomerase activity (Figure 2). The expression of telomerase in thyroid cancers was not correlated to age, histologic type, or the presence of lymph node metastasis (Table 1). However, three tumors of thyroid cancer had high telomerase activity (that is, retained a TRAP signal after a 100-fold dilution of the extract) whose representative results are shown in Figure

Table 1. Patient characteristics in thyroid cancer

\begin{tabular}{ccccc}
\hline Patient code & Sex/age & Pathology & Stage (TNM) & AMES risk $^{\text {a }}$ \\
\hline C502 & M/70 & Papillary & T4N1bM0 & High risk \\
C056 & F/19 & Papillary & T2N1bM0 & Low risk \\
C580 & F/39 & Papillary & T2N0M0 & Low risk \\
C154 & F/45 & Follicular & T3N0M0 & Low risk \\
C957 & F/58 & Squamous & T4N1bM0 & High risk \\
C799 & F/54 & Papillary & T4N1bM0 & High risk \\
C278 & F/29 & Papillary & T2N1bM0 & Low risk \\
C121 & F/64 & Papillary & T1N0M0 & Low risk \\
C871 & F/23 & Papillary & T2N1bM0 & Low risk \\
\hline
\end{tabular}

a AMES risk: age, metastasis, extracapsular tumor and size (Cady et al., 1988) 
Table 2. Patients characteristics in benign thyroid diseases

\begin{tabular}{ccll}
\hline Patient code & Sex/Age & \multicolumn{1}{c}{ Pathology } & Telomerase activity \\
\hline B119 & F/33 & Adenomatous hyperplasia & Positive \\
B200 & F/58 & Adenomatous hyperplasia & Positive \\
B116 & F/28 & Adenomatous hyperplasia & Positive \\
B456 & F/67 & Adenomatous hyperplasia & Negative \\
B002 & F/51 & Adenomatous hyperplasia & Negative \\
B932 & F/35 & Adenomatous hyperplasia & Positive \\
H586 & F/36 & Hashimotoís thyroiditis & Positive \\
H205 & F/31 & Hashimotoís thyroiditis & Positive \\
B632 & M/32 & Follicular adenoma & Negative \\
B640 & F/33 & Follicular adenoma & Negative \\
\hline
\end{tabular}

3 and six tumors had low telomerase activity. Interestingly, three patients with high telomerase activity were high clinical stage and high risk group by AMES risk analysis performed as described previously (Cady et al., 1988).

In 4 of 6 adenomatous hyperplasia telomerase activity was detected, whereas all the follicular adenoma were negative for telomerase activity (Table 2, Figure 3 ). The telomerase activity in benign thyroid nodules was detected in $0.6 \mu \mathrm{g}$ (10-fold dilution) but not in $0.06 \mu \mathrm{g}$ (100-fold dilution) of protein (Figure 4).

Hashimoto's thyroiditis tissues also revealed telomerase activity (Figure 3) being characterized by 6 base pair ladder pattern. With serial dilution of protein, the signal was only detected in 10-fold dilution (Figure 4)

\section{Discussion}

Telomerase activity has been detected in a wide variety of human tumors and tumor derived cell lines, whereas it was not detected in both normal cells in vitro and normal somatic tissues in vivo (Counter et al., 1994; Kim et al., 1994). Our study presented here is a systematic examination of telomerase activity in human benign and malignant thyroid nodules.

Telomerase activity was positive in 9 of 9 human thyroid cancer tissues (100\%), being characterized by the 6 base pair ladder pattern which has been seen consistently in human 293 kidney cell line as a positive control, whereas normal tissues did not show any telomerase activity. Such high positive rates were also demonstrated in our previous reports tested with head and neck cancer (89\%) (Ahn et al., 1995), gastric cancer (89\%) (Ahn et al., 1997), and cervical cancer tissues (89\%) (Noh et al., 1996). These findings suggest that telomerase activation may play a significant role in establishment and progression of cancer, irrespective of the tumor type.

All the six early staged tumors and three advanced staged tumors showed telomerase activity. These results indicate that telomerase activation may be present not only
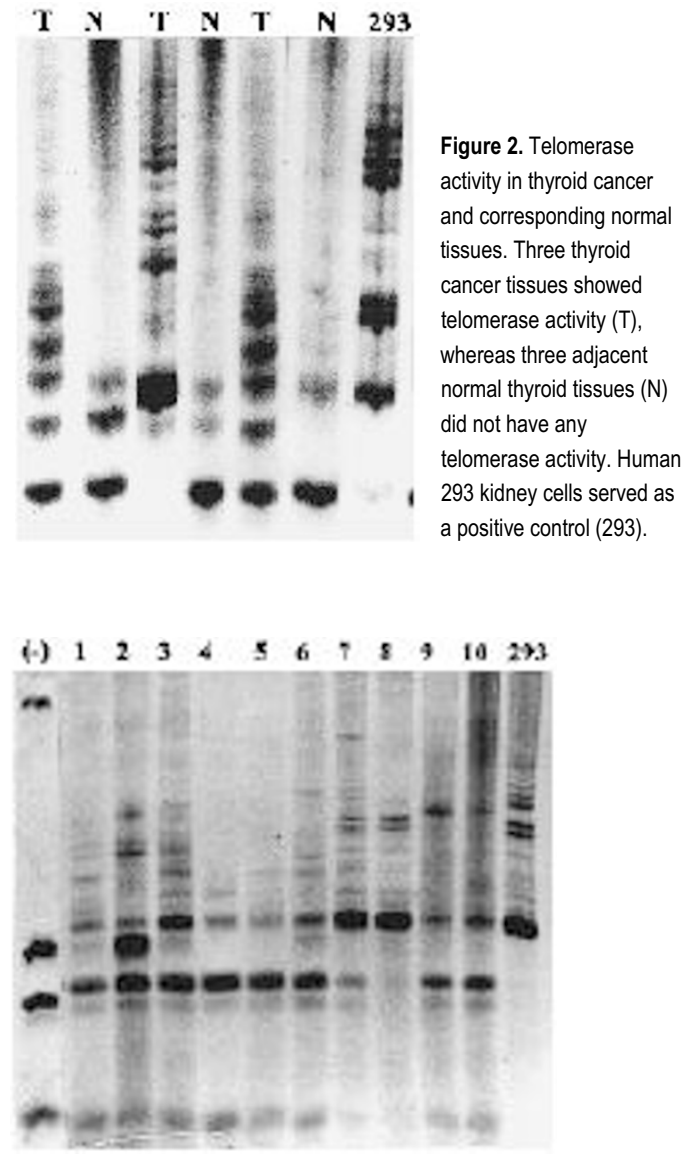

Figure 3. Representative results of telomerase activity in benign thyroid nodules. Four of 8 benign thyroid nodules (lanes 1-3,6) showed telomerase activity, and all the Hashimoto's thyroiditis tissues (lanes 7,8 ) also revealed telomerase activity.
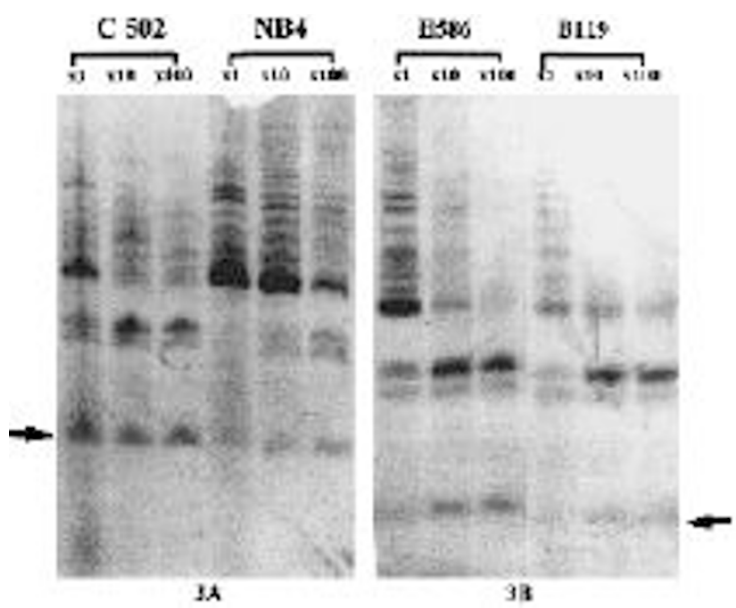

Figure 4. A 10- and 100-fold dilution of each of the extracts designated in Figure 1. Each extract prepared from tumor tissue was subjected to serial dilution and analyzed at $6 \mu \mathrm{g}$, at $0.6 \mu \mathrm{g}$ and at $0.06 \mu \mathrm{g}$ of protein. Compared to the NB4 leukemia cell line (NB4) and thyroid cancer tissue (C502) which have telomerase activity in 100-fold dilution, telomerase activity was detected only in 10 -fold dilution in benign thyroid nodules (B119) and Hashimoto's thyroiditis tissues (H586). 
in early but also in late stage of cancers. The incidence of telomerase activity in the thyroid cancer tissues was not correlated to age, tumor size, tumor stage, histologic findings or lymph node metastasis. Thyroid cancers with high telomerase activity by semiquantitative methods were high stage and an unfavorable prognosis, whereas tumors with low telomerase activity were associated with a favorable prognosis, suggesting that there may be different mechanisms regulating telomerase activity in thyroid carcinogenesis.

Some of the benign thyroid nodules (4 of 8 ) did show telomerase activity in three independent experiments. With semiquantitative methods, the telomerase activity found in benign thyroid nodules was lower compared to that of thyroid cancer tissues. However, further studies to determine the mechanism and the biological significance of telomerase activity in benign thyroid nodules should be warranted.

Hashimoto's thyroiditis tissues also revealed telomerase activity indicating that immune activated lymphocytes infiltrating in Hashimoto's thyroiditis tissues may account for telomerase positivity. Recent reports have shown that normal peripheral blood cells such as granulocytes, $T$ and B lymphocytes, and monocytes have weak telomerase activity and strong telomerase activity was also demonstrated even in normal mature cells of the immune system (Nisslon et al., 1994; Broccoli et al., 1995; Counter et al., 1995; Brousset et al., 1997).

In conclusion, the present study demonstrated that telomerase activity is highly positive in human thyroid cancer tissues, irrespective of the tumor size, stage, or histologic findings. These findings indicated that telomerase may be involved in malignant transformation and in progression of thyroid cancers. Further studies are necessary in order to fully understand the biological role of telomerase in thyroid cancinogenesis.

\section{References}

Ahn, M.-J., Noh, Y.-H. and Lee, Y.-S. (1995) Telomerase activity in head and neck cancer. Korean J. Biochem. 27: 219-223

Ahn, M.-J., Noh, Y.-H., Lee, Y.-S., Kim, I.-S., Choi., I.-Y., Lee, J.-S. and Lee, K.-H (1997) Telomerase activity and its clinicopathological signifi-cance in gastric cancer Eur. J. Cancer (in press)

Allsopp, R. C., Vaziri, H. and Petterson, C. (1992) Telomere length predicts replicative capacity of human fibroblasts. Proc. Natl. Acad. Sci. USA 89: 10114-10118

Broccoli, D., Young, J. W. and de Lange, T. (1995) Telomerase activity in normal and malignant hematopoietic cells. Proc. Natl. Acad. Sci. USA92: 9082-9086

Brousset, P., Saati, T., Chaouche, N., Zenou, R.C., Schlaifer, D., Chittal, S. and Delsol, G. (1997) Telomerase activity in reactive and neoplastic lymphoid tissues: infrequent detection of activity in Hodgkin's disease. Blood 89: 26-31

Cady, B. and Ross, R. (1988) An expanded view of risk group definition in differentiated thyroid carcinoma. Surgery 104: 947-953

Counter, C. M., Botelho, F. M., Wang, P., Harley, C. B. and Bacchetti S. (1994) Stabilization of short telomeres and telomerase activity accompany immortalization of Epstein-Barr virus transformed human B lymphocytes. J. Virol. 68: 3410-3414

Counter, C. M., Gupta, J., Harley, C. B., Leber, B. and Bacchetti, S. (1995) Telomerase activity in normal leukocytes and in hematologic malignancies. Blood 85: 2315-2320

Greider, C. W. and Blackburn, E.H. (1985) Identification of a specific telomere terminal transferase activity in Tetrahymena extracts. Cell 43: 405-413

Harley, C. B., Futcher, A. B. and Greider, C. W. (1990) Telomeres shortening during aging of human fibroblasts. Nature 345 : $458-460$

Hastie, N. D., Dempster, M., Dunlop, M. G., Thompson, A. M., Green, D. K. and Allshire, R. C. (1990) Telomere reduction in human colorectal carcinoma and with aging. Nature 346: 866-868

Hiyama E., Hiyama K., Yokoyama T., Matsuura Y., Piatyszek M. A. and Shay J. W. (1995) Correlating telomerase activity levels with human neuroblastoma outcomes. Nature Medicine 1: 249-255

Kim, N. W., Piatyszek, M. A., Prowse, K. R. et al. (1994) Specific associ-ation of human telomerase activity with immortal cells and cancer. Science 266: 2011-2015

Lindsey, J., McGill, N. I., Lindsey, L. A., Green, D. K. and Kooke, H. J. (1991) In vivo loss of telomeric repeats with age in humans. Mutat. Res. 256: 45-48

Nilsson, P., Mehle, C., Remes, K. and Roos, G. (1994) Telomerase activity in vivo human malignant hematopoietic cells. Oncogene 9: 3043-3048

Noh, Y.-H., Ahn, M.-J., Lee, Y.-S., Cho, S.-H., Kim, K.-S. and Hwang, Y.-Y. (1996) Telomerase activity in human cervical tissues: Comparison between invasive cervical carcinoma, carcinoma in situ, and dysplasia (abstract). Ann. Congr. Korean Cancer Assoc. 22: 148

Shay, J. W., Wright, W. E. and Werbin, H. (1991) Defining the molecular mechanisms of human cell immortalization. Biochim. Biophys. Acta 1072: 1-7

Stamps, A. C., Gusterson, B. A. and O'Hare, M. J. (1992) Are tumor immortal? Eur. J. Cancer 28A: 1495-1500

Vaziri, H., Dragowski, W., Allsopp, R. C., Thomas, T. E., Harley, C. B. and Lansdorp, P. M. (1994) Evidence for a mitotic clock in human hemato-poietic stem cells: loss of telomeric DNA with age. Proc. Natl. Acad. Sci. USA 91: 9857-9860

Wright W. E., Shay J. W. and Piatyszek M. A. (1995) Modifications of a telomeric repeat amplification protocol (TRAP) result in increased reliability, linearity, and sensitivity. Nucleic Acids Res. 23: 3794-3795

Yu, G. L., Bradley, J. D. and Attardi, L. D. (1990) In vivo alteration of telomerase sequence caused by mutated Tetrahymena telomerase RNAs. Nature 344: 126-132 